\title{
Absorptivity of brown carbon in fresh and photo-chemically aged biomass-burning emissions
}

\author{
R. Saleh ${ }^{1}$, C. J. Hennigan ${ }^{2}$, G. R. McMeeking ${ }^{3}$, W. K. Chuang ${ }^{1}$, E. S. Robinson ${ }^{1}$, H. Coe ${ }^{4}$, N. M. Donahue ${ }^{1}$, and \\ A. L. Robinson ${ }^{1}$ \\ ${ }^{1}$ Center for Atmospheric Particle Studies, Carnegie Mellon University, Pittsburgh PA, USA \\ ${ }^{2}$ Chemical, Biochemical, and Environmental Engineering, University of Maryland Baltimore County, Baltimore MD, USA \\ ${ }^{3}$ Droplet Measurement Technologies, Boulder CO, USA \\ ${ }^{4}$ Centre for Atmospheric Science, University of Manchester, Manchester, UK
}

Correspondence to: A. L. Robinson (alr@andrew.cmu.edu)

Received: 23 April 2013 - Published in Atmos. Chem. Phys. Discuss.: 2 May 2013

Revised: 2 July 2013 - Accepted: 3 July 2013 - Published: 9 August 2013

\begin{abstract}
Experiments were conducted to investigate light absorption of organic aerosol (OA) in fresh and photochemically aged biomass-burning emissions. The experiments considered residential hardwood fuel (oak) and fuels commonly consumed in wild-land and prescribed fires in the United States (pocosin pine and gallberry). Photochemical aging was performed in an environmental chamber. We constrained the effective light-absorption properties of the OA using conservative limiting assumptions, and found that both primary organic aerosol (POA) in the fresh emissions and secondary organic aerosol (SOA) produced by photo-chemical aging contain brown carbon, and absorb light to a significant extent. This work presents the first direct evidence that SOA produced in aged biomass-burning emissions is absorptive. For the investigated fuels, SOA is less absorptive than POA in the long visible, but exhibits stronger wavelength-dependence and is more absorptive in the short visible and near-UV. Light absorption by SOA in biomassburning emissions might be an important contributor to the global radiative forcing budget.
\end{abstract}

\section{Introduction}

Climate forcing calculations typically treat black carbon (BC) and dust as the only atmospheric particulate light absorbers. However, some organic aerosols (OA), referred to as brown carbon (BrC) (Andreae and Gelencsér, 2006), are also significant light absorbers. BrC occurs in biomass-burning emissions (e.g. Kirchstetter et al., 2004; Sandradewi et al., 2008; Habib et al., 2008; Lewis et al., 2008; Yang et al., 2009; Chen and Bond, 2010; Hecobian et al., 2010), which constitute three quarters of the total primary organic aerosol (POA) globally (Bond et al., 2004). Furthermore, biomass-burning emissions are photo-oxidized in the atmosphere, producing secondary organic aerosol (SOA) at concentrations similar to POA (Lee et al., 2008; Yokelson et al., 2009; Hennigan et al., 2011); to our knowledge, the light-absorption properties of this biomass-burning SOA have not yet been directly investigated.

Absorptivity of particulate matter (PM) is often quantified at a certain wavelength via a mass absorption cross-section (MAC, $\mathrm{m}^{2} \mathrm{~g}^{-1}$ ), with its wavelength dependence given by an Absorption Ångström Exponent (AAE) (MAC $\sim \lambda^{-A A E}$ ). Although convenient, these parameters are not fundamental. They depend on the particle size (Bond et al., 2006; Moosmüller et al., 2011), and when used to quantify absorptivity of $\mathrm{BC}$ mixed with $\mathrm{OA}$, they represent mass weighted averages of the OA and BC. Thus, MAC and AAE measured for certain emissions cannot be generally applied to aerosols with different size distributions and OA-to-BC ratios.

With recent developments in the ability of global and regional transport models to track PM composition and size (e.g. Chen et al., 2010; Murphy and Pandis, 2010), light absorption can be calculated using Mie-theory if the complex refractive index ( $m=n-\mathrm{i} k$ ) of the different PM components is known, assuming that the particles are spherical and homogeneous. While $m$ of $\mathrm{BC}$ and $n$ of $\mathrm{OA}$ and inorganics have 
been extensively studied (e.g. Bond et al., 2006; Bond and Bergstrom, 2005; Hand and Kreidenweis, 2002; Levin et al., $2010)$, data on $k$ values of atmospheric OA $\left(k_{\mathrm{OA}}\right)$ are scarce.

Several methods have been employed to determine $k_{\mathrm{OA}}$. One technique involves extracting OA in a solvent and measuring bulk absorption of the extracts (Kirchstetter et al., 2004; Chen and Bond, 2010; Hoffer et al., 2006), with different solvents yielding different $k_{\mathrm{OA}}$ values because they extract different fractions of the OA (Chen and Bond, 2010). Alexander et al. (2008) used Transmission Electron Microscopy (TEM) to determine the dielectric function, from which refractive indices of individual particles were calculated. While this method has the advantage of probing individual particles rather than an ensemble, it cannot isolate the optical properties of $\mathrm{OA}$ if it is internally mixed with $\mathrm{BC}$, as is often the case for biomass-burning PM and aged atmospheric aerosols. A third method employs Mie-theory to obtain optical closure on light absorption and scattering measurements and retrieve refractive indices of the PM (Chakrabarty et al., 2010; Lack et al., 2012). Chakrabarty et al. (2010) applied this method to determine refractive indices of PM in duff-burning emissions. Due to the smoldering burning conditions, the emissions were dominated by $\mathrm{OA}$ and contained negligible amounts of BC.

The retrieval of OA optical properties via optical closure becomes more complicated if the $\mathrm{OA}$ is internally-mixed with $\mathrm{BC}$. OA, which can form a coating over $\mathrm{BC}$ particles, both absorbs and refracts light into the $\mathrm{BC}$ core, enhancing its absorption. Light absorption by such particles depends on core size as well as coating thickness, in addition to the refractive indices; thus, detailed optical modeling is required. If the particles are assumed to be spherical, and exhibit coreshell morphology with a homogenous shell, a core-shell Mietheory model can be employed (Lack et al., 2012). Although the recent study by Cappa et al. (2012) proposed that coreshell morphology is unlikely for aged urban aerosol, BC in biomass-burning emissions is most likely coated by OA. Upon combustion, BC particles form initially at high temperatures, and act as condensation sites for OA. Lack et al. (2012) reported that core-shell morphology was required to explain absorption by particles in biomass-burning plumes over Colorado.

Here, we use optical closure to determine the imaginary part of the refractive indices of OA in fresh and photochemically aged biomass-burning emissions. We perform optical closure for two cases. In the first case, $\mathrm{OA}$ and $\mathrm{BC}$ are assumed to be externally-mixed. In the second case, BC is assumed to be internally-mixed with OA, exhibiting coreshell morphology. While real particle morphologies are almost certainly more complex, these two cases provide conservative limits to the recovered optical properties of the OA. The derived imaginary part of the refractive indices can be used in chemical transport models employing Mie-theory to predict light absorption for different atmospheric conditions.

\section{Methods}

\subsection{Experimental}

Experiments were conducted at Carnegie Mellon University (CMU) and at the US Fire Science Laboratory as part of the Fire Lab at Missoula Experiment campaign (FLAME 3). The CMU experiments featured emissions from wood-burning (oak) in a residential stove, and the FLAME experiments examined small-scale open burns of fuels consumed by wildland and prescribed fires in the US (gallberry, and pocosin pine). In both cases, emissions were diluted and injected into a smog chamber, and then exposed to UV lights to initiate photo-oxidation, generating SOA. Details of the basic experimental set up and procedure are in Hennigan et al. (2010, 2011). For the fresh primary emissions, the analysis was performed on measurements half an hour immediately before turning on the UV lights. For the photo-chemically aged condition, the measurements were taken after one hour of exposure to the UV lights. Although the amount of aging (exposure to UV lights) in the experiments was relatively modest, appreciable amounts of SOA were generated. For gallberry, we present data for the fresh emissions only, because we could not obtain reliable light absorption measurements of the aged emissions due to low particle concentrations.

Aerosol size distributions were measured using a scanning mobility particle sizer (SMPS, TSI). The size distribution of BC was measured using a Single Particle Soot Photometer (SP2, DMT). To calibrate the SP2 incandescence signal, a suspension of aquadag in water was atomized and dried. Monodisperse aquadag particles were then size selected using a differential mobility analyser (DMA). The particle mobility was converted to mass assuming spherical particles and a density of $1 \mathrm{~g} \mathrm{~cm}^{-3}$. The $\mathrm{BC}$ mass distributions measured using the SP2 were converted to number distributions assuming spherical particles and a density of $1.8 \mathrm{~g} \mathrm{~cm}^{-3}$.

Mass concentration of non-refractory material was measured using a High Resolution Aerosol Mass Spectrometer (HR-AMS, Aerodyne) and Quadrupole AMS (Q-AMS, Aerodyne) in CMU and FLAME experiments, respectively. For all experiments, non-refractory aerosol mass was dominated by organics $(>95 \%)$ as shown in Fig. S1. A 7wavelength Aethalometer (Magee Scientific, model AE-31) was used to obtain the wavelength-dependence of the absorption coefficients, with data points at wavelengths $(\lambda)$ of 370 , $470,520,590,660,880$, and $950 \mathrm{~nm}$.

\subsection{Optical closure}

\subsubsection{Approach}

The imaginary part of the refractive index of $\mathrm{OA}\left(k_{\mathrm{OA}}\right)$ was obtained using combined model calculations and light absorption measurements, as well as measurements of total and $\mathrm{BC}$ size distributions. 
Model calculations of absorption coefficients $\left(b_{\text {abs,model }}\right)$ were performed using a size-resolved core-shell Mie-theory model based on the formulation of Bohren and Huffmann (1983) for coated spheres. We extended the computer code for light absorption cross-sections of a single spherical particle by Mätzler (2002) to calculate absorption coefficients of a polydisperse particle distribution, and to account for coating using Eq. (8.2) in Bohren and Huffmann (1983).

Inputs to the Mie-theory model are: (1) BC and OA size distributions, which were determined from SP2 and SMPS measurements as described in section 2.2.3;2) $\mathrm{BC}$ refractive index, $m_{\mathrm{BC}}=1.85-0.71 \mathrm{i}$ (Bond and Bergstrom, 2005); and 3) OA real part of the refractive index, $n_{\mathrm{OA}}=1.55$ (Bond et al., 2006; Lack and Cappa, 2010; Hand and Kreidenweis, 2002). The shape of the absorption coefficient curve, i.e. the wavelength dependence of $b_{\mathrm{abs} \text {,model }}$ was constrained using Aethalometer measurements as described in Sect. 2.2.2. We assume that $k_{\mathrm{OA}}$ has a power-law wavelength dependence (Lack and Cappa, 2010; Sun et al., 2007), and express it as $k_{O A, 550}(550 / \lambda)^{w}$, where $k_{O A, 550}$ is the imaginary part of the refractive index at $\lambda=550 \mathrm{~nm}$. $k_{O A, 550}$ and $w$ are the free parameters in the model.

The optimization procedure for determination of $k_{O A, 550}$ and $w$ involves the following steps: (1) $\mathrm{BC}$ and $\mathrm{OA}$ size distributions are determined from SP2 and SMPS measurements; (2) these size distributions are used in conjunction with Mie-theory to constrain the magnitude of the absorption coefficient; (3) the wavelength dependence of the absorption coefficient (or AAE) is inferred from Aethalometer measurements; (4) Mie-theory calculations are performed to find the best theoretical fit to the measurement-constrained absorption coefficients (determined from steps 2 and 3). These steps are described in details in Sects. 2.2.2 and 2.2.3.

$k_{\mathrm{OA}}$ values of POA were determined from measurements of fresh emissions that were sampled into the smog chamber. To estimate $k_{\mathrm{OA}}$ of SOA, we assume that the aged OA is wellmixed and that its $k_{\mathrm{OA}}$ is a mass-weighted average of those of POA and SOA. The concentration of SOA in the aged OA was determined using the method of Hildebrandt et al. (2009) as described in Supplement (SI).

An implicit assumption in the Mie-theory analysis is that $\mathrm{BC}$ is spherical. This assumption is reasonable when $\mathrm{BC}$ acquires an organic coating since $\mathrm{BC}$ agglomerates are compacted upon coating (Bond et al., 2006; Cross et al., 2010; Zhang et al., 2008; Gyawali et al., 2009), and has been employed previously to model absorption of biomass-burning emissions (Lack et al., 2012).

Another implicit assumption is that the $\mathrm{BrC}$ size distribution in the emissions is similar to that of OA. This is justified because POA forms by rapid quenching of organic vapors in the cooling plume and subsequent condensation on available seed particles. There is no reason for $\mathrm{BrC}$ (or other $\mathrm{OA}$ components) to exhibit preferential condensation on certain particles because when the hot vapors are quenched, they are highly supersaturated and will condense on any surface avail- able. Thus, we expect the POA composition to be fairly uniform among all particle sizes. SOA is also expected to be uniformly distributed among all particles. When SOA forms by oxidation of organic vapors, it condenses on all particles to maintain similar mass fraction (activity) in all particle sizes. Using AMS particle time of flight (pTOF) data, it has been shown that SOA composition is uniform among all particles sizes for both biomass-burning (Grieshop et al., 2009) and diesel (Donahue et al., 2012) emissions.

\subsubsection{Using Aethalometer measurements to constrain the wavelength dependence of the absorption coefficients}

The wavelength-dependent absorption coefficient $\left(b_{\mathrm{abs}}\right)$ can be determined from Aethalometer measurements as:

$b_{\mathrm{abs}, \mathrm{AET}}(\lambda)=\operatorname{MAC}_{\mathrm{AET}} C_{\mathrm{BC}, \mathrm{AET}}$

Where $\mathrm{MAC}_{\mathrm{AET}}=14625 / \lambda\left(\mathrm{m}^{2} \mathrm{~g}^{-1}\right)$ is the manufacturer's specified mass absorption cross-section, and $C_{\mathrm{BC}, \mathrm{AET}}$ is the $\mathrm{BC}$ concentration reported by the instrument. The value of $b_{\text {abs, AET }}$ requires corrections due to particle loading (Arnott et al., 2005; Kirchstetter and Novakov, 2007) and multiple scattering (Weingartner et al., 2003) as described in the SI.

There are concerns that artifacts associated with organic loading on the Aethalometer filter may bias $b_{\mathrm{abs}, \mathrm{AET}}$ (Lack et al., 2008; Cappa et al., 2008). In particular, the organics can spread on the filter (Subramanian et al., 2007) and enhance scattering in the filter matrix (Lack et al., 2008; Cappa et al., 2008). This enhancement in scattering could be misinterpreted as absorption, and thus lead to overestimation in the magnitude of the absorption coefficients.

To avoid these potential biases, we do not use $b_{\text {abs, AET }}$ to quantify the magnitude of the absorption coefficient, but only to determine its wavelength dependence (shape of the curve, or AAE):

$b_{\text {abs,norm }}(\lambda)=\frac{b_{\text {abs, AET }}(\lambda)}{b_{\text {abs,AET }}(950 \mathrm{~nm})}$

The artifacts associated with OA loading do not have a sig-

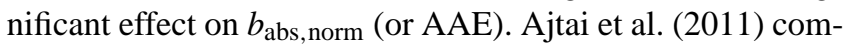
pared AAE derived from Aethalometer measurements and a Photo-Acoustic Spectrometer ( $4 \lambda$-PAS). Measurements were performed in a suburban site near Budapest, Hungary during the winter, when the ambient PM was dominated by biomass-burning emissions. They found that $\mathrm{AAE}_{\text {Aethalometer }}$ and $\mathrm{AAE}_{4 \lambda-\mathrm{PAS}}$ were similar, with $\mathrm{AAE}_{\text {Aethalometer being }}$

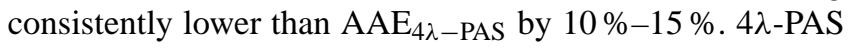
measures the absorption coefficient of an ensemble of aerosol particles at 4 wavelengths $(266,355,532$, and $1064 \mathrm{~nm})$ while suspended. Thus, the agreement between the two instruments indicates that $b_{\mathrm{abs}, \text { norm }}$ (or AAE) derived from aethalometer measurements is not altered due to collection on the filter. 
To further evaluate any effect of artifacts due to OA filter loading on the wavelength dependence of $b_{\mathrm{abs}, \mathrm{AET}}$, we compared $b_{\text {abs,norm }}$ immediately prior to and following filtertape advance (Fig. S2). The Aethalometer collects PM on a spot on the filter tape for absorption measurements, and after a certain loading is attained, it advances to a new spot. The measurement made immediately prior to tape advance is the most susceptible to artifacts (has the highest accumulated OA mass loading) while the measurement made immediately following the advance is the least susceptible (has the lowest OA loading). As shown in Fig. S2, the AAE increased by around $10 \%$ immediately following the tape advance. This indicates that the OA loading had a small effect on the wavelength dependence of $b_{\mathrm{abs}, \mathrm{AET}}$ in these experiments. Similar, but more pronounced effects were observed by Rizzo et al. (2011) who reported $40 \%$ decrease in AAE for biomassburning emissions in the Amazon Basin due to OA loading.

The data used in the analysis were taken from measurements well before the end of the Aethalometer filter cycle, thus the bias in AAE is considerably less than $10 \%$. Therefore, we ignore the decrease in AAE and assume that $b_{\mathrm{abs}, \text { norm }}$ is not affected by OA loading. We note that this assumption is conservative from the perspective of possible OA absorption, because it minimizes the contribution of OA to total absorption at short wavelengths, and thus minimizes $k_{\mathrm{OA}}$.

\subsubsection{Determination of $k_{\mathrm{OA}}$}

As described in the previous section, Aethalometer measurements were used to constrain the wavelength dependence of $b_{\mathrm{abs}}$. The magnitude of $b_{\mathrm{abs}}$ was determined by assuming that $\mathrm{OA}$ absorbs negligibly at $950 \mathrm{~nm}$ (the longest wavelength of Aethalometer measurements) and using the Mietheory model combined with PM size distributions obtained from SP2 and SMPS measurements (details can be found in Sect. 3.2) to calculate $b_{\text {abs }}$ at $950 \mathrm{~nm}$ :

$b_{\mathrm{abs}}=b_{\mathrm{abs}, \operatorname{model}}(950 \mathrm{~nm}) b_{\mathrm{abs}, \text { norm }}$

The assumption that OA absorbs negligibly at the long visible wavelengths is justified based on numerous findings reported in the literature (e.g. Kirchstetter et a., 2004; Chen and Bond, 2010; Chakrabarty et al., 2010; Lack et al., 2012).

The value of $b_{\mathrm{abs} \text {, model }}(950 \mathrm{~nm})$, and thus the derived $k_{\mathrm{OA}}$, depends on the mixing state of OA and BC (Lack and Cappa 2010; Lack et al., 2012). If BC and OA are externally mixed, OA will have no contribution to $b_{\mathrm{abs}, \text { model }}(950 \mathrm{~nm})$. However, if $\mathrm{BC}$ is coated with organics, $b_{\text {abs,model }}(950 \mathrm{~nm})$ will be enhanced due to light refraction by the organic shell, with the enhancement being a function of the shell thickness (Bond et al., 2006; Lack and Cappa, 2010; Schnaiter et al., 2005; Zhang et al., 2008). Since the true mixing state of the aerosol is not known, we performed the analysis for the two limiting cases illustrated in Fig. 1.

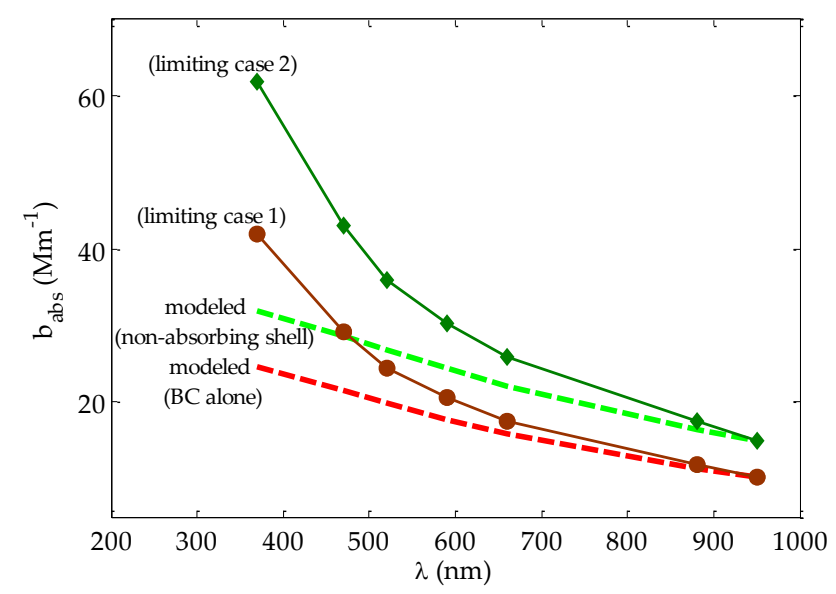

Fig. 1. The two limiting cases described in Sect. 2.2.3 to determine measurement-constrained absorption coefficients. Data (symbols) are from the fresh pocosin pine measurements.

In limiting case $1, \mathrm{BC}$ and $\mathrm{OA}$ are assumed to be externally-mixed. The dashed red curve in Fig. 1 corresponds to $b_{\mathrm{abs}, \text { model }}$ of $\mathrm{BC}$ alone (assuming that $\mathrm{OA}$ does not contribute to absorption). $b_{\text {abs,model }}(950 \mathrm{~nm})$ is estimated using Mie-theory in conjunction with the BC size distribution measured using the SP2. Equations (2) and (3) are then combined to obtain the measurement-constrained $b_{\text {abs }}$ (brown circles). The difference between the dashed red curve and the brown circles is the contribution of OA to absorption for this limiting case.

In limiting case 2, each $\mathrm{BC}$ particle is assumed to have acquired the maximum possible OA coating (see Sect. 3.2). The dashed green curve in Fig. 1 corresponds to $b_{\mathrm{abs} \text {, model }}$ of $\mathrm{BC}$ coated with non-absorbing OA, and the dark green diamonds are the measurement-constrained $b_{\text {abs }}$. For this limiting case, $b_{\text {abs,model }}(950 \mathrm{~nm})$ is estimated using core-shell Mie-theory calculations, where the size distribution of the $\mathrm{BC}$ cores is obtained using the SP2, and the organic coating thickness is obtained from combining SP2 and SMPS measurements as described in Sect. 3.2. The difference between the dashed green curve and the dark green diamonds is the contribution of OA to absorption.

As evident in Fig. 1, the contribution of OA to absorption in limiting case 2 is larger than limiting case 1 . Any other mixing state (varying amount of coating) would yield an OA contribution to absorption within these two limits. Thus, limiting cases 1 and 2 provide a lower and upper bound of $k_{\mathrm{OA}}$, respectively. 


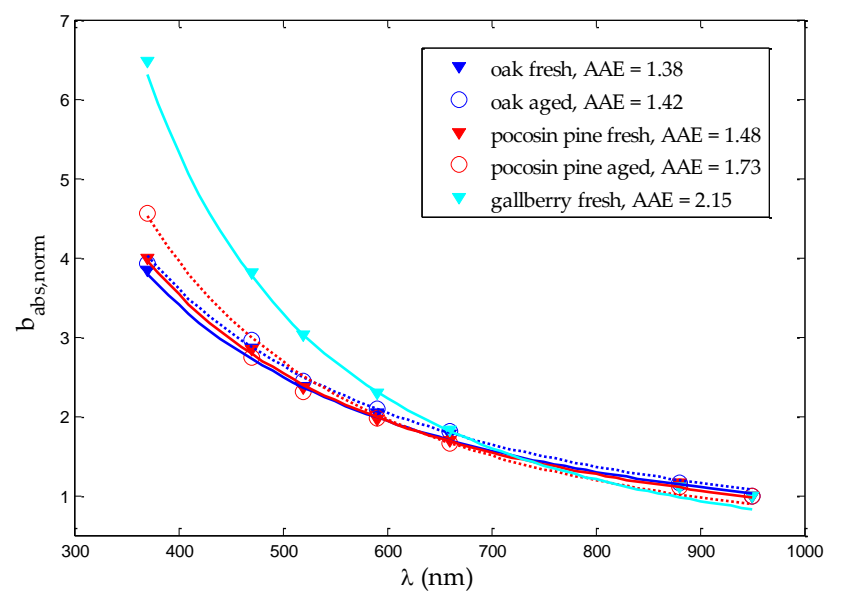

Fig. 2. Absorption coefficients of fresh and aged emissions measured using the Aethalometer normalized by absorption coefficient values at $950 \mathrm{~nm}$. Solid lines are power-law fits with AAE values given in the legend.

\section{Results}

\subsection{Normalized absorption coefficients and Absorption Ångström Exponents}

Figure 2 shows normalized absorption coefficients $\left(b_{\text {abs, norm }}\right.$, Eq. 2) at 7 wavelengths between 370 and $950 \mathrm{~nm}$ measured using the Aethalometer for fresh and photo-chemically aged emissions. Also shown in Fig. 2 are power-law fits, from which AAE can be determined. AAE for the investigated fuels are 1.38 for fresh oak, 1.42 for aged oak, 1.48 for fresh pocosin pine, 1.73 for aged pocosin pine, and 2.15 for fresh gallberry. These values are consistent with previous findings reported in the literature for biomass-burning emissions (Sandradewi et al., 2008; Gyawali et al., 2009; Habib et al., 2008).

$\mathrm{BC}$ has been shown to have $\mathrm{AAE} \approx 1$ (Bergstrom et al., 2002; Schnaiter et al., 2005; Kirchstetter et al., 2004), and measured AAE values greater than 1 are interpreted as evidence of BrC (Kirchstetter et al, 2004; Sandradewi et al., 2008; Chen and Bond, 2010; Sun et al., 2007; Clarke et al., 2007; Hecobian et al., 2010; Zhang et al., 2011; Cheng et al., 2011). Thus, the AAE values obtained here indicate that both fresh and photo-chemically aged PM might contain BrC.

One limitation of the analysis presented in Fig. 2 is that AAE does not provide quantitative information on the absorptivity of OA, as it depends on the size distribution and the mixing state of $\mathrm{BC}$ and $\mathrm{OA}$. For example, Gyawali et al. (2009) showed that non-absorbing shells over BC cores can lead to AAE greater or less than unity, as the absorption enhancement by lensing can have a direct or inverse wavelength-dependence. Consequently, relying solely on AAE might result in an underestimation or overestimation of the absorptivity of OA. To obtain quantitative constraints on OA absorptivity, we performed optical closure analysis.

\section{2 $\mathrm{BC}$ and $\mathrm{OA}$ size distributions and mixing state}

Optical closure using Mie-theory calculations requires the knowledge of $\mathrm{BC}$ and $\mathrm{OA}$ size distributions and their mixing state. The total $(\mathrm{BC}+\mathrm{OA})$ and $\mathrm{BC}$ size distributions were measured using an SMPS and SP2, respectively. Due to instrument limitations, reliable BC size distribution measurements were obtained for volume equivalent diameters in the range $150 \mathrm{~nm}-400 \mathrm{~nm}$. As shown in Fig. 3a, we fit the BC volume distribution with a lognormal function to extend it to smaller and larger sizes. The SP2 captures the peak of the $\mathrm{BC}$ volume distribution (around $200 \mathrm{~nm}$ ), and therefore provides a good constraint on the $\mathrm{BC}$ volume distribution if it is mono-modal.

Figure $3 \mathrm{~b}$ shows the total size distribution measured by the SMPS and the BC size distribution derived from the SP2 measurements. Assuming that $\mathrm{BC}$ and $\mathrm{OA}$ are externallymixed (limiting case 1), the OA number distribution can be estimated as the difference between the total and the BC number distributions. It is shown by the dotted magenta curve in Fig. 3b.

Limiting case 2 corresponds to BC being internally-mixed with $\mathrm{OA}$, with $\mathrm{BC}$ particles acquiring maximum possible organic coating. To estimate the maximum coating as a function of $\mathrm{BC}$ particle size, we hypothesize that $\mathrm{BC}$ particles form initially upon combustion, and as the emissions temperature drops, organics start to condense on the BC seeds. Starting with the BC size distribution (derived from SP2 measurements) as the initial condition, we simulated the condensation kinetics assuming that the coated $\mathrm{BC}$ size distribution cannot grow beyond the total size distribution measured by the SMPS. The final coated BC size distribution (green curve in Fig. 3c) corresponds to the maximum possible coating. The difference between the total (measured by SMPS) and coated BC (simulated) size distributions corresponds to the externally-mixed OA particle size distribution. We note that the externally-mixed OA constituted $70 \%-75 \%$ of the total OA in our experiments by mass, which is in good agreement with the observation (83\%) reported by Lack et al. (2012) in biomass-burning plumes over Colorado.

\subsection{SOA formation}

Figure 4 shows time series of particle mass concentration derived from SMPS measurements and normalized by initial concentration $\left(C_{\text {norm }}\right)$ for the oak and pocosin-pine experiments. $C_{\text {norm }}$ decays due to wall-loss in the smog chamber. Time $t=0$ indicates when the UV lights were turned on and thus the onset of photo-oxidation. The increase in aerosol concentration due to SOA formation is plainly evident in the "bump" immediately after photo-oxidation is initiated, which is eventually obscured by wall loss. Figure 4 

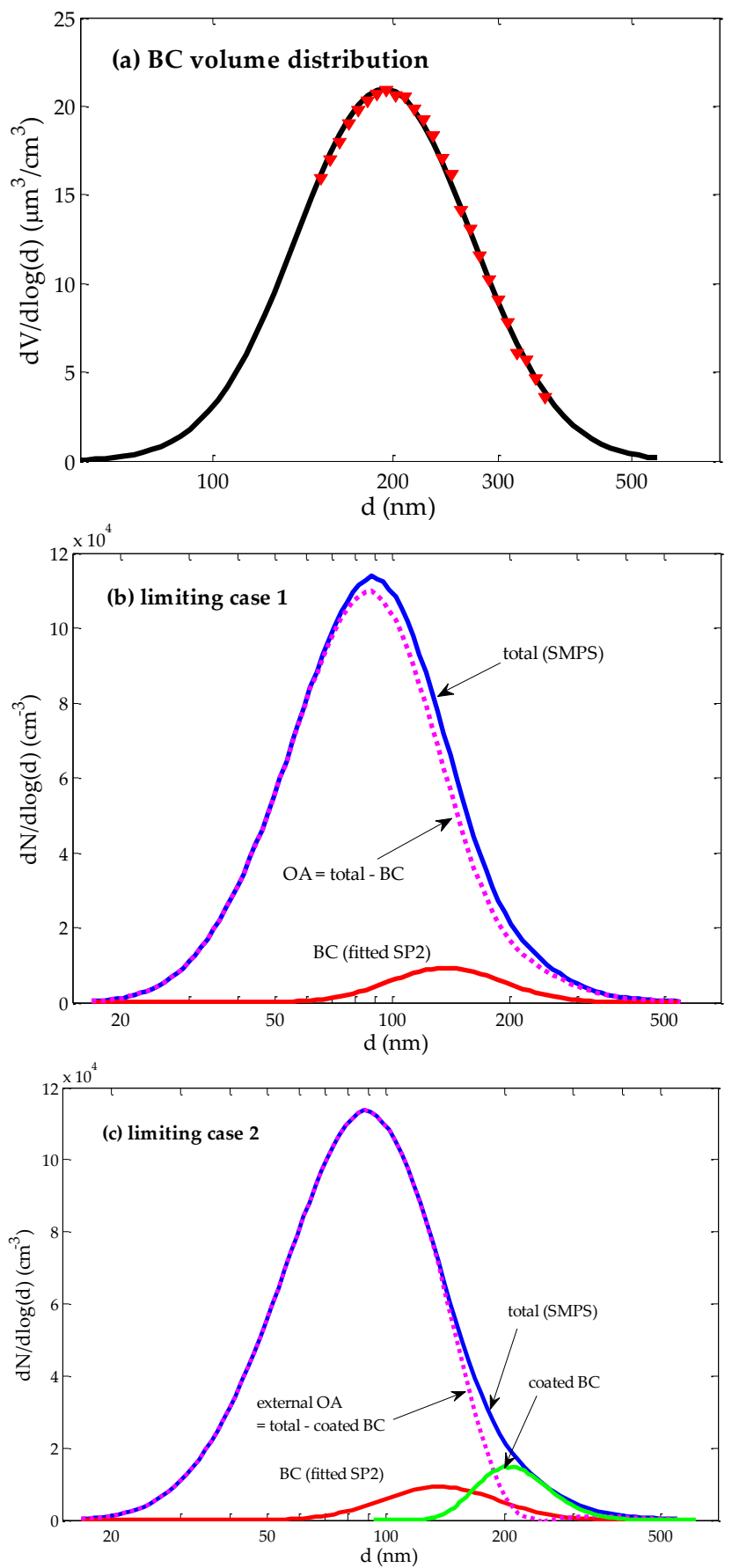

Fig. 3. Measured size distributions from fresh oak experiment. (a) $\mathrm{BC}$ volume distribution inferred from SP2 measurements (red diamonds) and lognormal fit (solid black). (b) Total (SMPS), BC (fit to SP2 data), and OA (difference between total and BC) number distributions for limiting case 1 (external-mixing). (c) Total, externallymixed $\mathrm{OA}$, and internally-mixed (BC coated with $\mathrm{OA}$ ) number distributions for limiting case 2 .

also shows SOA-to-OA ratios estimated using the method of Hildebrandt et al. (2009) (see Supplement). In both experiments, significant amounts of SOA were generated, with

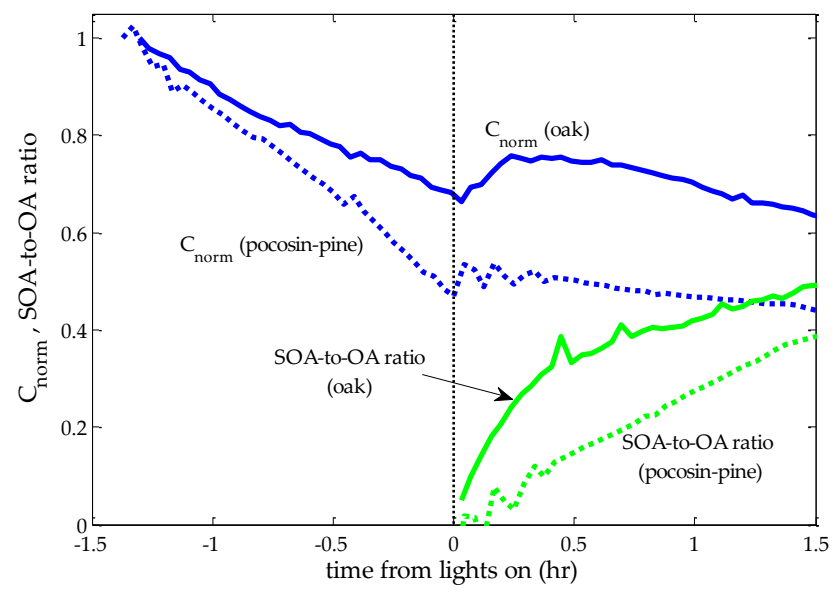

Fig. 4. Time series of OA concentrations normalized by initial concentrations, and SOA formation rate upon photo-oxidation.

end-of-experiment concentrations in the suspended aerosol similar to those of POA. We note that SOA-to-OA ratios calculated here constitute a lower bound, because in our analysis we assume that POA is conserved upon aging. However, as shown by Hennigan et al. (2011), a fraction of the POA likely evaporates as semi-volatile vapors are oxidized.

\subsection{Absorptivity of OA}

Measurement-constrained absorption coefficients estimated using Eq. (3) are shown in Fig. 5 (black diamonds) for the two limiting cases described in Sect. 2.2.3. Also shown are Mie-theory calculations for different assumptions on OA absorptivity and mixing state. The red curves correspond to OA being non-absorptive $\left(k_{\mathrm{OA}}=0\right)$ and externally mixed with $\mathrm{BC}$, thus absorption is due to $\mathrm{BC}$ only. The green curves were obtained by assuming that $\mathrm{OA}$ is non-absorbing, but coats the $\mathrm{BC}$ and thus enhances its absorption. The cyan curves assume that only POA is absorptive in the aged aerosol $\left(k_{\mathrm{POA}}\right.$ is obtained from fresh measurements). The blue curves correspond to calculations performed using the optimum value of $k_{\mathrm{OA}}$ to fit the measurement-constrained absorption coefficients.

For both limiting cases, absorption of $\mathrm{BC}$ alone (or $\mathrm{BC}$ coated with non-absorbing $\mathrm{OA}$ ) cannot reproduce the shape of the measurement-constrained absorption coefficients of the fresh emissions. POA must contribute to absorption (i.e. contain $\mathrm{BrC}$ ) for the model to fit the observations. Furthermore, if SOA in the aged aerosol is assumed to be nonabsorbing, the model calculations fall below the measurements at short wavelengths, indicating that SOA is also absorptive. The derived $k_{\mathrm{OA}}$ values are given in Table 1 , and plotted as a function of wavelength in Fig. 6 .

Limiting case 2 (core-shell) yields $k_{\mathrm{OA}}$ values that are on average a factor 4-5 larger than limiting case 1 (externalmixing). Within each limiting case, there is a spread of a 

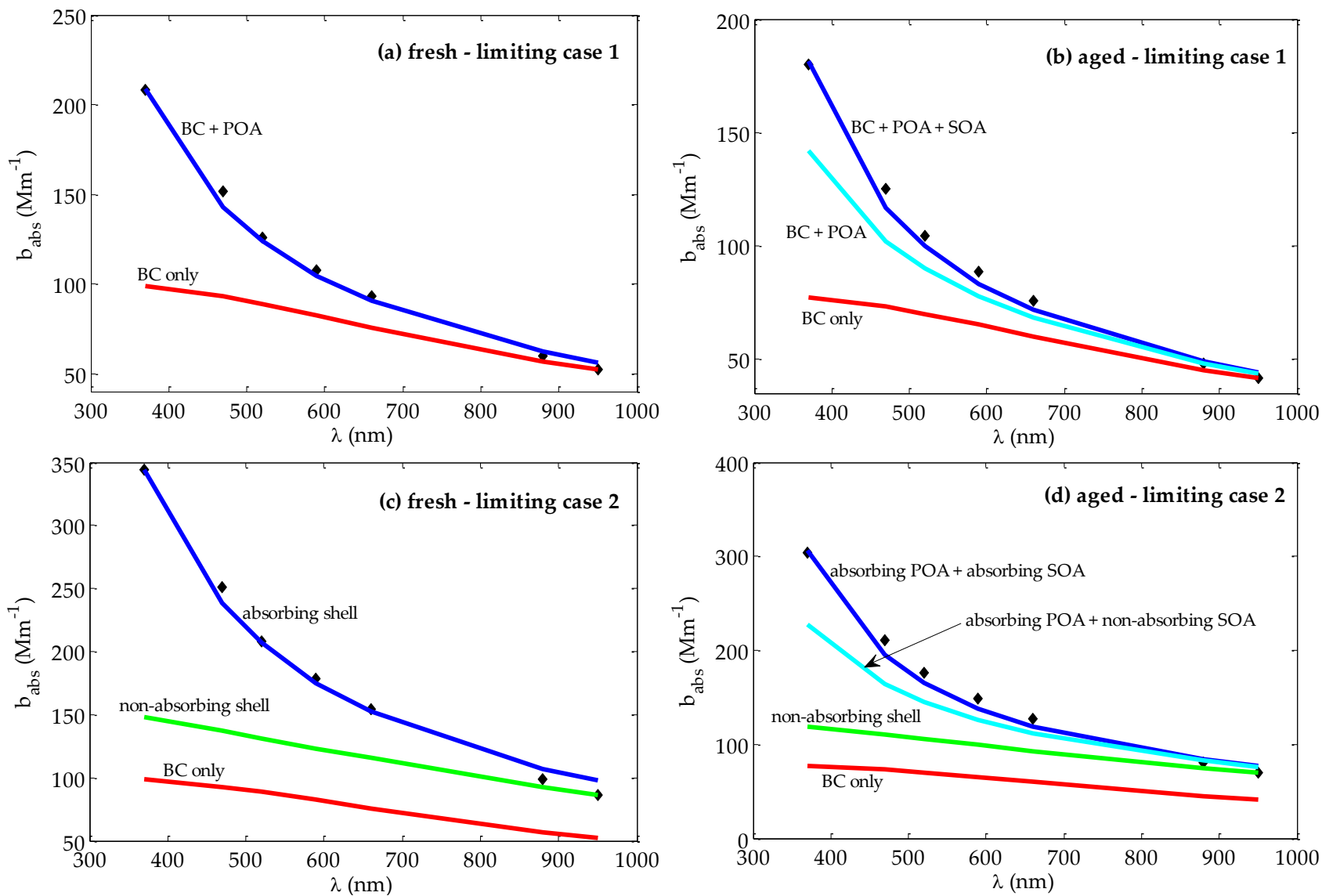

Fig. 5. Measurement-constrained absorption coefficients (black diamonds), and model calculations using different assumptions on OA absorptivity (solid lines) for (a) fresh oak emissions and assuming external-mixing (limiting case 1), (b) aged oak emissions and assuming external-mixing (limiting case 1), (c) fresh oak emissions and assuming core-shell morphology (limiting case 2), and (d) aged oak emissions and assuming core-shell morphology (limiting case 2). See Sect. 3.4 for description of calculations associated with each curve. The same data are plotted on a log-log scale in Fig. S4.

Table 1. Imaginary part of the refractive indices of the organics in the investigated fuels at $550 \mathrm{~nm}$ and their wavelength dependence $\left(k_{\mathrm{OA}}=\right.$ $\left.k_{\mathrm{OA}, 550}(550 / \lambda)^{w}\right)$. The uncertainty in $k_{\mathrm{OA}}$ values is approximately $\pm 50 \%$.

\begin{tabular}{llcccc}
\hline Fuel & & \multicolumn{2}{c}{ Limiting case 1 (external-mixing) } & Limiting case 2 (core-shell) \\
\hline \multirow{4}{*}{ Oak } & & $k_{\mathbf{O A}, \mathbf{5 5 0}}$ & $w$ & $k_{\mathbf{O A}, \mathbf{5 5 0}}$ & $w$ \\
& POA & 0.02 & 2.2 & 0.06 & 2.1 \\
\multirow{2}{*}{ Pocosin Pine } & SOA & 0.014 & 3 & 0.05 & 3 \\
\multirow{4}{*}{ Galberry } & POA & 0.015 & 2.9 & 0.04 & 3.2 \\
& SOA & 0.01 & 4 & 0.03 & 4.4 \\
& POA & 0.0055 & 2.4 & 0.022 & 2.6 \\
\hline
\end{tabular}

factor of 3 across the three fuel samples investigated fuels. This spread might be due to difference in fuel types as well as burning conditions (Chen and Bond, 2010). This suggests that a more comprehensive dataset investigating a wide range of fuel types and burning conditions is required to constrain $k_{\mathrm{OA}}$ of biomass-burning emissions.

\section{Discussion}

\subsection{Uncertainty in the derived $k_{\mathrm{OA}}$ values}

In this section, we discuss the potential uncertainty created by the assumptions employed in the optical closure analysis. The largest contributor to uncertainty in $k_{\mathrm{OA}}$ is mixing state. We explicitly addressed this uncertainty by considering 
the two limiting cases described in Sect. 2.2.3. As shown in Fig. 6, limiting case 2 (core-shell) yields $k_{\mathrm{OA}}$ values that are on average a factor of 4-5 larger than limiting case 1 (external-mixing); both cases show significant absorption by both POA and SOA. We note that for the experiments in this study, where substantial amount of OA are generated (as in biomass-burning emissions in general), limiting case 2 (coreshell) is more likely to resemble the mixing state of $\mathrm{BC}$. $\mathrm{OA}$ condenses onto the $\mathrm{BC}$ particles when the emissions are cooled, creating a core-shell morphology.

For each of the limiting cases, the assumption that $\mathrm{OA}$ absorbs negligibly at $950 \mathrm{~nm}$ yields a lower bound on the derived $k_{\mathrm{OA}}$ values. Finite $\mathrm{OA}$ absorptivity at shorter wavelengths is dictated by the shape of the absorption curve obtained from Aethalometer measurements. If, for instance, we assume that $\mathrm{OA}$ is non-absorbing at $550 \mathrm{~nm}$ (Lack et al., 2012), we would obtain nonphysical negative absorptivity at longer wavelengths, as illustrated in Fig. S3.

As described in Sect. 2.2.3, the magnitude of the measurement-constrained absorption coefficients is constrained by the magnitude of $\mathrm{BC}$ absorption at $950 \mathrm{~nm}$, which is dictated by the BC size distribution determined from SP2 measurements. As shown in Sect. 3.2 and Fig. 2, we construct the $\mathrm{BC}$ size distributions assuming that they are lognormal, and that there are no other peaks of the volume distribution below the SP2 detection limit. If there were other peaks, our lognormal fits would lead to underestimation of BC concentration, and thus underestimation of $\mathrm{BC}$ absorption at 950 $\mathrm{nm}$. This translates into lower bounds on the magnitude of the absorption coefficients, and consequently the derived $k_{\mathrm{OA}}$ values.

There is minimal uncertainty associated with the Aethalometer measurements since they were used to determine only the wavelength dependency, not the magnitude, of the absorption coefficients. As described in Sect. 2.2.2, measurement biases due to OA loading likely cause a decrease in relative absorption at short wavelengths (decrease in AAE), and can potentially lead to a slight underestimation of $k_{\mathrm{OA}}$ values.

Other contributors to uncertainty in $k_{\mathrm{OA}}$ are uncertainties in OA and BC concentrations due to uncertainties in SMPS and SP2 measurements. We consider $20 \%$ uncertainty in SMPS (Khlystov et al., 2004) and SP2 measurements. Other minor sources of uncertainty are the assumption on $m_{\mathrm{BC}}$, which we assume to have the range (1.75-0.63i, 1.95-0.79i) reported by Bond and Bergstrom (2005), and $n_{\mathrm{OA}}$, which we assume to range between 1.41 and 1.61 (Levin et al., 2010). Sensitivity calculations reveal that uncertainties in these parameters yield a maximum combined uncertainty of approximately $\pm 50 \%$ in the derived $k_{\mathrm{OA}}$ values.
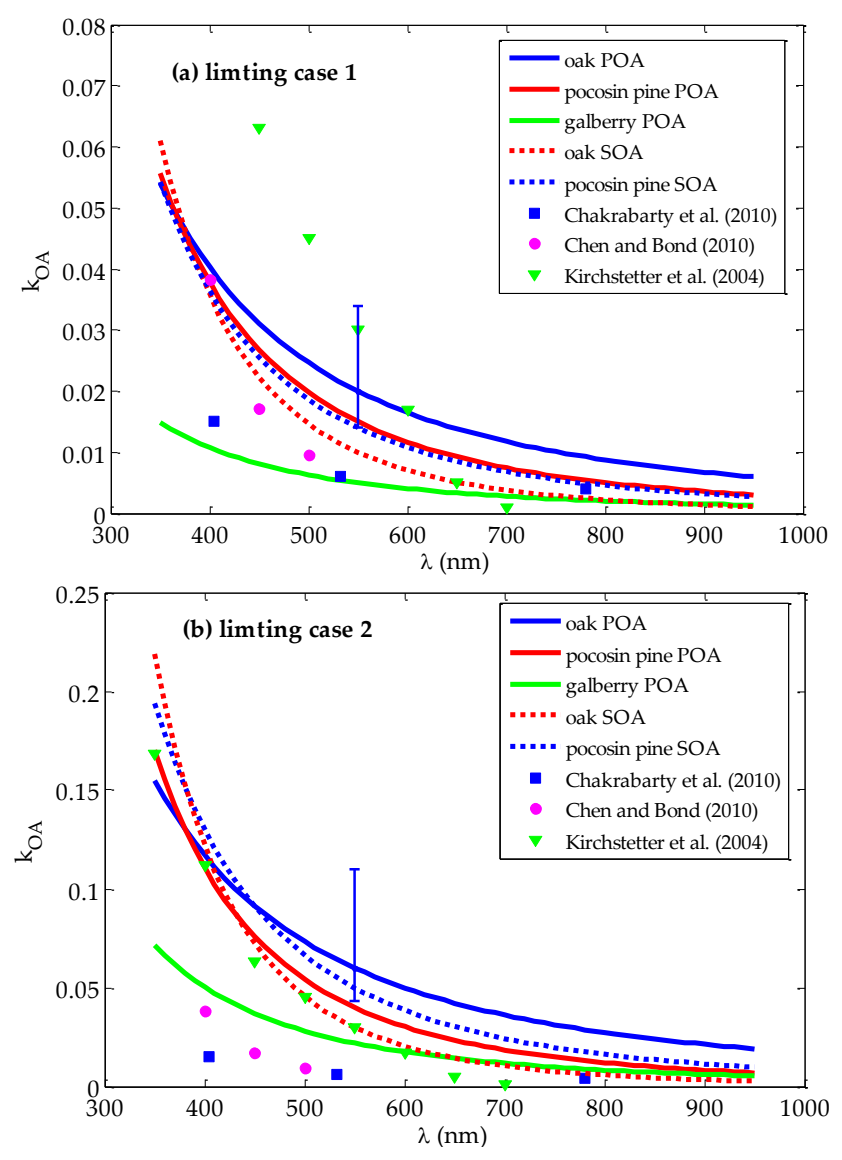

Fig. 6. Estimated imaginary part of the refractive indices of POA and SOA for the fuels investigated in this study for (a) limiting case 1 (external-mixing assumption) and (b) limiting case 2 (core-shell assumption). The blue error-bars represent the uncertainty in $k_{\mathrm{OA}}$ of oak POA at $\lambda=550 \mathrm{~nm}$; other fuels exhibit similar relative uncertainties. Also shown here are $k_{\mathrm{OA}}$ values of biomass-burning emissions reported by previous studies (see Sect. 4.2 for details).

\subsection{Comparison with previous studies}

Figure 6 compares our findings with $k_{\mathrm{OA}}$ of biomass-burning emissions reported in the literature. Chen and Bond (2010) measured the absorptivity of oak pyrolysis emissions extracted in methanol. Chakrabarty et al. (2010) determined $k_{\mathrm{OA}}$ of $\mathrm{BrC}$ in "tar balls" from smoldering duff burning using online absorption and scattering measurements coupled with Mie-theory optical closure. Kirchstetter et al. (2004) estimated $k_{\mathrm{OA}}$ of emissions from savanna fires and wood burning based on the difference in absorption of samples before and after treatment with acetone.

Our derived $k_{\mathrm{OA}}$ for limiting case 1 (external-mixing) are bounded by the $k_{\mathrm{OA}}$ values of Chakrabarty et al. (2010) and Kirchstetter et al. (2004). For limiting case 2 (core-shell), our $k_{\mathrm{OA}}$ values are larger than the values of Chakrabarty et al. (2010) and Chen and Bond (2010), but are in good agreement with Kirchstetter et al. (2004) at short wavelengths. We 
note that the work of Chakrabarty et al. (2010) and Chen and Bond (2010) investigated emissions of low-temperature combustion and pyrolysis which produced only OA (no BC). This form of combustion might produce OA with substantially lower absorptivity than high-temperature combustion (which produces both OA and BC) investigated in this study. On the other hand, the burning conditions in Kirchstetter et al. (2004) were similar to those in our study, which may explain the closer agreement in $k_{\mathrm{OA}}$.

\subsection{Absorption by biomass-burning SOA}

It has been shown that SOA from biogenic and anthropogenic precursors absorbs light (Hecobian et al., 2010; Zhang et al., 2011; Cheng et al., 2011; Nakayama et al., 2010; Zhong and Jang 2011; Lambe et al., 2013). However, to our knowledge, this work presents the first direct evidence that SOA formed by photo-oxidation of biomass-burning emissions is light-absorbing. While other studies (e.g. Kirchstetter et al., 2004; Alexander et al., 2008; Lack et al., 2012) have investigated aged biomass-burning emissions in the atmosphere, which potentially contain SOA, the absorptivity of the SOA portion has not been constrained. For both oak and pocosin pine, SOA absorbs light less efficiently than POA in the long visible wavelengths, however it exhibits a stronger wavelength dependence and is more absorptive than POA in the short visible and near-UV. This might be due to differences in chemical composition, namely higher aromaticity in POA, but the true cause is not known. This hypothesis is supported by the recent findings of Lambe et al. (2013) who reported that SOA from aromatic precursors can retain lightabsorbing conjugated double bonds, while light-absorption in SOA from non-aromatic precursors is due to carboxylic and carbonyl functional groups. Thus, $\mathrm{BrC}$ in POA and SOA in biomass-burning emissions may have overlapping as well as different chromophores. Desyaterik et al. (2013) investigated composition of $\mathrm{BrC}$ in cloud water droplets that were heavily affected by biomass-burning. They found that most of $\mathrm{BrC}$ absorption is due to aromatic carbonyls, which exist in fresh biomass-burning emissions, and nitrated phenols, which form through gas phase and aqueous chemistry. Nitrated phenols were also observed by Mohr et al. (2013) in biomass-burning plumes over Delting, United Kingdom.

Some field studies have reported significant amounts of SOA formation from photo-oxidation of biomass-burning emissions, with SOA-to-POA ratios up to two (Lee et al., 2008; Yokelson et al., 2009). Light absorption by biomassburning SOA is thus a potentially important contributor to the global radiative forcing budget. The values of the imaginary part of the refractive indices provided here can be applied in models employing Mie-theory to perform preliminary calculations to assess the extent of SOA light absorption.

\section{Supplementary material related to this article is available online at: http://www.atmos-chem-phys.net/13/ 7683/2013/acp-13-7683-2013-supplement..zip.}

Acknowledgements. The authors acknowledge Sonia M. Kreidenweis, Cyle E. Wold, and Wei Min Hao for organizing the FLAME 3 campaign, and Spyros Pandis and Peter Adams for their valuable comments. This work was supported by the National Park Service and Joint Fire Science Programme and the EPA STAR program through the National Center for Environmental Research (NCER) under grant R833747 and the Department of Energy Atmospheric Sciences Research programme through grant DESC0007075. This paper has not been subject to EPA's required peer and policy review, and therefore does not necessarily reflect the views of the Agency. No official endorsement should be inferred.

Edited by: V. Faye McNeill

\section{References}

Ajtai, T., Filep, Á., Utry, N., Schnaiter, M., Linke, C., Bozóki, Z., Szabó., G., and Leisner, T.: Inter-comparison of optical absorption coefficients of atmospheric aerosols determined by a multiwavelength photoacoustic spectrometer and an Aethalometer under sub-urban wintry conditions, J. Aerosol. Sci., 42, 859-866, 2011.

Andreae, M. O. and Gelencsér, A.: Black carbon or brown carbon? The nature of light-absorbing carbonaceous aerosols, Atmos. Chem. Phys., 6, 3131-3148, doi:10.5194/acp-6-3131-2006, 2006.

Alexander, D. L. T., Crozier, P. A., and Anderson, J. R.: Brown carbon spheres in East Asian outflow and their optical properties, Science, 321, 833-836, doi:10.1126/science.1155296, 2008.

Arnott, W. P., Hamasha, K., Moosmuller, K., Sheridan, P. J., and Ogren, J. A.: Towards light absorption measurements with a 7wavelength aethalometer: evaluation with a photoacoustic instrument and a 3-wavelenght nephelometer, Aerosol. Sci. Tech., 39, 17-29, 2005.

Bergstrom, R. W., Russell, P. B., and Hignett, P.: The wavelength dependence of black carbon particles: predictions and results from the Tarfox experiment implications for the aerosol single scattering albedo, J. Atmos. Sci., 59, 567-577, 2002.

Bohren, C. F. and Huffman, D. R.: Absorption and Scattering of Light by Small Particles, John Wiley \& Sons, New York, 1983.

Bond, T. C., Anderson, T. L., and Campbell, D.: Calibration and intercomparison of filter-based measurements of visible light absorption by aerosols, Aerosol. Sci. Tech., 30, 582-600, 1999.

Bond, T. C., Streets, D. G., Yarber, K. F., Nelson, S. M., Woo, J., and Klimont, Z.: A technologically-based global inventory of black and organic carbon emissions from combustion, J. Geophys. Res., 109, D14203, doi:10.1029/2003JD003697, 2004.

Bond, T. C. and Bergstrom, R. W.: Light absorption by carbonaceous particles: an investigative review, Aerosol. Sci. Tech., 39, $1-40,2005$. 
Bond, T. C., Habib, G., and Bergstrom, R. W.: Limitations in the enhancement of visible light absorption due to mixing state, Geophys. Res. Lett., 111, D20211, doi:10.1029/2006JD007315, 2006.

Cappa, C. D., Lack, D. A., Burkholder, J. B., and Ravishankara, A. R.: Bias in filer-based aerosol light absorption measurements due to organic aerosol loading: evidence from laboratory measurements, Aerosol. Sci. Tech., 42, 1022-1032, 2008.

Cappa, C. D., Onasch, T. B., Massoli, P., Worsnop, D. R., Bates, T. S., Cross, E. S., Davidovits., P., Hakala, J., Hayden, K. L., Jobson, B. T., Kolesar, K. R., Lack, D. A., Lerner, B. M., Li, S.M., Mellon, D., Nuaaman, I., Olfert, J. S., Petäjä, T., Quinn, P. K., Song, C., Subramanian, R., Williams, E. J., and Zaveri, R. A.: Radiative absorption enhancements due to the mixing state of atmospheric black carbon, Science, 337, 1078-1081, 2012.

Chakrabarty, R. K., Moosmüller, H., Chen, L.-W. A., Lewis, K., Arnott, W. P., Mazzoleni, C., Dubey, M. K., Wold, C. E., Hao, W. M., and Kreidenweis, S. M.: Brown carbon in tar balls from smoldering biomass combustion, Atmos. Chem. Phys., 10, 6363-6370, doi:10.5194/acp-10-6363-2010, 2010.

Chen, W.-T., Lee, Y. H., Adams, P. J., Nenes, A., and Seinfeld, J. H.: Will black carbon mitigation dampen aerosol indirect forcing?, Geophys. Res. Lett., 37, L09801, doi:10.1029/2010GL042886, 2010.

Chen, Y. and Bond, T. C.: Light absorption by organic carbon from wood combustion, Atmos. Chem. Phys., 10, 1773-1787, doi:10.5194/acp-10-1773-2010, 2010.

Cheng, Y., He, K.-B., Zheng, M., Duan, F.-K., Du, Z.-Y., Ma, Y.L., Tan, J.-H., Yang, F.-M., Liu, J.-M., Zhang, X.-L., Weber, R. J., Bergin, M. H., and Russell, A. G.: Mass absorption efficiency of elemental carbon and water-soluble organic carbon in Beijing, China, Atmos. Chem. Phys., 11, 11497-11510, doi:10.5194/acp11-11497-2011, 2011.

Clarke, A., McNaughton, C., Kapustin, V., Shinozuka, Y., Howell, S., Dibb, J., Zhou, J., Anderson, B., Brekhovskikh, V., Turner, H., and Pinkerton, M.: Biomass burning and pollution aerosol over North America: organic components and their influence on spectral optical properties and humidification response, J. Geophys. Res., 112, D12S18, doi:10.1029/2006JD007777, 2007.

Cross, E. S., Onasch, T. B., Ahern, A., Wrobel, W., Slowik, J. G., Olfert, J., Lack, D. A., Massoli, P., Cappa, C. D., Schwarz, J. P., Spackman, J. R., Fahey, D. W., Sedlacek, A., Trimborn, A., Jayne, J. T., Freedman, A., Williams, L. R., Ng, N. L., Mazzoleni, C., Dubey, M., Brem, B., Kok, G., Subramanian, R., Freitag, S., Clarke, A., Thornhill, D., Marr, L. C., Kolb, C. E., Worsnop, D. R., and Davidovits, P.: Soot particle studdies - instrument intercomparison - project overview, Aerosol. Sci. Tech., 44, 592-611, 2010.

Desayterik, Y., Sun, Y., Shen, X., Lee, T., Wang, X., Wang, T., and Collet Jr., J. L.: Speciation of "brown" carbon in cloud water impacted by agricultural biomass burning in Eastern China, J. Geophys. Res., 118, 7389-7399, doi:10.1002/jgrd.50561, 2013.

Donahue, N. M., Robinson, A. L., Trump, E. R., Riipinnen, I., and Kroll, J. H.: Volatility and aging of atmospheric organic aerosol, Top. Curr. Chem., doi:10.1007/128, 2012.

Grieshop, A. P., Miracolo, M. A., Donahue, N. M., and Robinson, A. L.: Constraining the volatility distribution and gasparticle partitioning of combustion aerosols using isothermal dilution and thermodenuder measurements, Environ. Sci. Technol.,
43, 4750-4756, 2009.

Grieshop, A. P., Donahue, N. M., and Robinson, A. L.: Laboratory investigation of photochemical oxidation of organic aerosol from wood fires 2: analysis of aerosol mass spectrometer data, Atmos. Chem. Phys., 9, 2227-2240, doi:10.5194/acp-9-2227-2009, 2009.

Gyawali, M., Arnott, W. P., Lewis, K., and Moosmüller, H.: In situ aerosol optics in Reno, NV, USA during and after the summer 2008 California wildfires and the influence of absorbing and non-absorbing organic coatings on spectral light absorption, Atmos. Chem. Phys., 9, 8007-8015, doi:10.5194/acp-9-8007-2009, 2009.

Habib, G., Venkataraman, C., Bond, T. C., and Schauer, J. J.: Chemical, microphysical and optical properties of primary particles from the combustion of biomass fuels, Environ. Sci. Technol., 42, 8829-8834, 2008.

Hand, L. H. and Kreidenweis, S. M.: A new method for retrieving particle refractive index and effective density from aerosol size distribution data, Aerosol. Sci. Tech., 36, 1012-1026, 2002.

Hecobian, A., Zhang, X., Zheng, M., Frank, N., Edgerton, E. S., and Weber, R. J.: Water-Soluble Organic Aerosol material and the light-absorption characteristics of aqueous extracts measured over the Southeastern United States, Atmos. Chem. Phys., 10, 5965-5977, doi:10.5194/acp-10-5965-2010, 2010.

Hennigan, C. J., Sullivan, A. P., Collett, J. L., and Robinson, A. L.: Levoglucosan stability in biomass burning particles exposed to hydroxyl radicals, Geophys. Res. Lett., 37, L09806, doi:10.1029/2010GL043088, 2010.

Hennigan, C. J., Miracolo, M. A., Engelhart, G. J., May, A. A., Presto, A. A., Lee, T., Sullivan, A. P., McMeeking, G. R., Coe, H., Wold, C. E., Hao, W.-M., Gilman, J. B., Kuster, W. C., de Gouw, J., Schichtel, B. A., J. L. Collett Jr., Kreidenweis, S. M., and Robinson, A. L.: Chemical and physical transformations of organic aerosol from the photo-oxidation of open biomass burning emissions in an environmental chamber, Atmos. Chem. Phys., 11, 7669-7686, doi:10.5194/acp-11-7669-2011, 2011.

Hildebrandt, L., Donahue, N. M., and Pandis, S. N.: High formation of secondary organic aerosol from the photo-oxidation of toluene, Atmos. Chem. Phys., 9, 2973-2986, doi:10.5194/acp-92973-2009, 2009.

Hoffer, A., Gelencsér, A., Guyon, P., Kiss, G., Schmid, O., Frank, G. P., Artaxo, P., and Andreae, M. O.: Optical properties of humic-like substances (HULIS) in biomass-burning aerosols, Atmos. Chem. Phys., 6, 3563-3570, doi:10.5194/acp-6-35632006, 2006.

Khlystov, A. Stanier, C., and Pandis, S. N.: An algorithm for combining electrical mobility and aerodynamic size distributions data when measuring ambient aerosol, Aerosol. Sci. Tech., 38, 229238, 2004.

Kirchstetter, T. W., Novakov, T., and Hobbs, P. V.: Evidence that the spectral dependence of light absorption by aerosols is affected by organic carbon, J. Geophys. Res., 109, D21208, doi:10.1029/2004JD004999, 2004.

Kirchstetter, T. W. and Novakov, T.: Controlled generation of black carbon particles from a diffusion flame and applications in evaluating black carbon measurement methods, Atmos. Environ., 41, 1874-1888, 2007.

Lack, D. A., Cappa, C. D., Covert, D. S., Baynard, T., Massoli, P., Sierau, B., Bates, T. S., Quinn, P. K., Lovejoy, E. R., and Ravis- 
hankara, A. R.: Bias in filter-based aerosol light absorption measurements due to organic aerosol loading: Evidence from ambient measurements, Aerosol. Sci. Tech., 42, 1033-1041, 2008.

Lack, D. A. and Cappa, C. D.: Impact of brown and clear carbon on light absorption enhancement, single scatter albedo and absorption wavelength dependence of black carbon, Atmos. Chem. Phys., 10, 4207-4220, doi:10.5194/acp-10-4207-2010, 2010.

Lack, D. A., Langridge, J. M., Bahreini, R., Cappa, C. D., Middlebrook, A. M., and Schwarz, J. P.: Brown carbon and internal mixing in biomass burning particles, P. Natl. Acad. Sci. USA, 109, 14802-14807, 2012.

Lambe, E. T., Cappa, C. D., Massoli, P., Onasch, T. B., Forestieri, S. D., Martin, A. T., Cummings, M. J., Croasdale, D. R., Brune, W. H., Worsnop, D. R., and Davidovits, P.: Relationship between oxidation level and optical properties of secondary organic aerosol, Environ. Sci. Technol., 47, 6349-6357, 2013.

Lee, S., Kim, H. K., Yan, B., Cobb, C. E., Hennigan, C., Nichols, S., Chamber, M., Edgerton, E. S., Jansen, J. J., Hu, Y., Zheng, M., Weber, R. J., and Russell, A. G.: Diagnosis of aged prescribed burning plumes impacting an urban area, Environ. Sci. Technol., 42, 1438-1444, 2008.

Levin, E. T., McMeeking, G. R., Carrico, C. M., Mack, L. E., Kreidenweis, S. M., Wold, C. E., Moosmüller, H., Arnott, W. P., Hao, W. M., Collett Jr., J. L., and Malm, W. C.: Biomass burning smoke aerosol properties measured during Fire Laboratory at Missoula Experiment (FLAME), J. Geophys. Res., 115, D18210, doi:10.1029/2009JD013601, 2010.

Lewis, K., Arnott, W. P., Moosmüller, H., and Wold, C. E.: Strong spectral variation of biomass smoke light absorption and single scattering albedo observed with a novel dual-wavelength photoacoustic instrument, J. Geophys. Res., 113, D16203, doi:10.1029/2007JD009699, 2008.

Mätzler, C.: MATLAB functions for Mie scattering and absorption, Res Rep 2002-08, Inst. Für Angew. Phys., Bern, 2002.

Mohr, C., Lopez-Hilfiker, F. D., Zotter, P., Prevot, A. S. H., Xu, L., Ng, N. L., Herndon, S. C., Williams, L. R., Franklin, J. P., Zahniser, M. S., Worsnop, D. R., Knighton, W. B., Aiken, A. C., Gorkowski, K. J., Dubey, M. K., Allan, J. D., and Thornton, J. A.: Contribution of nitrated phenols to wood burning brown carbon light absorption in Delting, United Kingdom during winter time, Environ. Sci. Technol., 47, 6316-6324, 2013.

Moosmüller, H., Chakrabarty, R. K., Ehlers, K. M., and Arnott, W. P.: Absorption Ångström coefficient, brown carbon, and aerosols: basic concepts, bulk matter, and spherical particles, Atmos. Chem. Phys., 11, 1217-1225, doi:10.5194/acp-11-12172011, 2011.

Murphy, B. N. and Pandis, S. N.: Exploring summertime organic aerosol formation in the eastern United States using a regionalscale budget approach and ambient measurements, J. Geophys. Res., 115, D24216, doi:10.1029/2010JD014418, 2010.
Nakayama, T., Matsumi, Y., Sato, K., Imamura, T., Yamazaki, A., and Uchiyama, A.: Laboratory studies on optical properties of secondary organic aerosols generated during the photooxidation of toluene and the ozonolysis of alpha-pinene, J. Geophys. Res., 115, D24204, doi:10.1029/2010JD014387, 2010.

Rizzo, L. V., Correia, A. L., Artaxo, P., Procópio, A. S., and Andreae, M. O.: Spectral dependence of aerosol light absorption over the Amazon Basin, Atmos. Chem. Phys., 11, 8899-8912, doi:10.5194/acp-11-8899-2011, 2011.

Sandradewi, J., Prévôt, A. S. H., Weingartner, E., Schmidhauser, R., Gysel, M., and Baltensperger, U.: A study of wood burning and traffic aerosols in an Alpine valley using a multi-wavelength Aethalometer, Atmos. Environ., 42, 101-112, 2008.

Schnaiter, M., Linke, C., Möhler, O., Naumann, K.-H., Saathoff, H., Wagner, R., and Schurath, U.: Absorption amplification of black carbon internally mixed with secondary organic aerosol, J. Geophys. Res., 110, D19204, doi:10.1029/2005JD006046, 2005.

Subramanian, R., Roden, C. A., Boparai, P., and Bond, T. C.: Yellow beads and missing particles: trouble ahead for filter-based absorption measurements, Aerosol Sci. Tech., 41, 630-637, 2007.

Sun, H., Biedermann, L., and Bond, T. C.: Color of brown carbon: a model for ultraviolet and visible light absorption by organic carbon aerosol, Geophys. Res. Lett., 34, L17813, doi:10.1029/2007GL029797, 2007.

Weingartner, E., Saathoff, H., Schnaiter, M., Streit, N., Bitnar, B., and Baltensperger, U.: Absorption of light by soot particles: determination of the absorption coefficient by means of aethalometers, J. Aerosol. Sci., 34, 1445-1463, 2003.

Yang, M., Howell, S. G., Zhuang, J., and Huebert, B. J.: Attribution of aerosol light absorption to black carbon, brown carbon, and dust in China - interpretations of atmospheric measurements during EAST-AIRE, Atmos. Chem. Phys., 9, 2035-2050, doi:10.5194/acp-9-2035-2009, 2009.

Yokelson, R. J., Crounse, J. D., DeCarlo, P. F., Karl, T., Urbanski, S., Atlas, E., Campos, T., Shinozuka, Y., Kapustin, V., Clarke, A. D., Weinheimer, A., Knapp, D. J., Montzka, D. D., Holloway, J., Weibring, P., Flocke, F., Zheng, W., Toohey, D., Wennberg, P. O., Wiedinmyer, C., Mauldin, L., Fried, A., Richter, D., Walega, J., Jimenez, J. L., Adachi, K., Buseck, P. R., Hall, S. R., and Shetter, R.: Emissions from biomass burning in the Yucatan, Atmos. Chem. Phys., 9, 5785-5812, doi:10.5194/acp-9-5785-2009, 2009.

Zhang, R., Khalizof, A. F., Pagels, J., Zhang, D., Xue, H., and McMurry, P. H.: Variability in morphology, hygroscopicity, and optical properties of soot aerosols during atmospheric processing, P. Natl. Acad. Sci. USA, 105, 10291-10296, 2008.

Zhang, X., Lin, Y.-H., Surratt, J. D., Zotter, P., Prévôt, A. S. H., and Weber, R. J.: Light-absorbing soluble organic aerosol in Los Angeles and Atlanta: A contrast in secondary organic aerosol, Geophys. Res. Lett., 38, L21810, 2011.

Zhong, M. and Jang, M.: Light absorption coefficient measurement of SOA using a UV-Visible spectrometer connected with an integrating sphere, Atmos. Environ., 45, 4263-4271, 2011. 